\title{
The synthesis and nanostructure investigation of noble metal-based nanocomposite materials
}

\author{
Małgorzata Zienkiewicz-Strzałka ${ }^{1, \star}$ (1), Anna Deryło-Marczewska ${ }^{1}$, and Stanisław Pikus ${ }^{2}$ \\ 'Department of Physical Chemistry, Institute of Chemical Sciences, Maria Curie-Sklodowska University, 3, Sq. Maria Curie- \\ Sklodowska, 20-031 Lublin, Poland \\ ${ }^{2}$ Department of General and Coordination Chemistry and Crystallography, Faculty of Chemistry, Institute of Chemical Sciences, \\ Maria Curie-Sklodowska University, 3, Sq. Maria Curie-Sklodowska, 20-031 Lublin, Poland
}

Received: 6 January 2021

Accepted: 22 April 2021

Published online:

6 May 2021

(C) The Author(s) 2021

\section{ABSTRACT}

The presented work follows the theme of applied chemistry toward nanomaterials and multiphase functional systems of practical importance. Structural studies of nanocomposite materials are important due to the correlation between physicochemical/structural properties and their application potential. In this work, we report the fabrication and structural characterization of nanocomposite materials constituting noble metal (plasmonic) nanoparticles (AgNP and AuNP) dispersed on selected types of nanostructured solid hosts (nonporous silica, microporous activated carbon, chitosan biopolymer, and ordered mesoporous silica). The ability to maintain a dispersed state of colloidal precursors throughout their deposition on solid hosts was assessed. The influence of the carrier role in the formation and stabilization of nanometallic phases was evaluated taking into account the physicochemical and textural properties of the support surfaces. The size and shape of nanoobjects, clustering effects, interfacial properties, and stability of the immobilized nanophase were implemented by analyzing relevant parameters of SAXS analysis. The dimensional characteristic of the scatterers was evaluated by volume-weighted particle size distribution $\operatorname{Dv}(R)$. The detailed overall shape and maximal particle dimension were described by the analysis of pair distance distribution functions (PDDFs). The radius of gyration $\left(R_{\mathrm{g}}\right)$ from PDDF and Guinier approximation was calculated for illustrating the dimension of scattered heterogeneities in the investigated solids. The asymptotic behavior of a scattering curve and Porod theory were applied for determining the diffusion and quality of the interfacial surfaces. The size and morphology of nanoparticles in colloidal precursor solutions have been defined as spherical and bimodal in size ( $\sim 6 \mathrm{~nm}$ and $20 \mathrm{~nm})$. It was observed that the spherical shape and dispersed state of nanoparticles were

Handling Editor: Naiqin Zhao.

Address correspondence to E-mail: malgorzata.zienkiewicz@poczta.umcs.lublin.pl 
achieved for all systems after deposition. However, the morphology of their final form was conditioned by the solid matrices. The particle properties from SAXS were correlated with properties determined by TEM and low-temperature nitrogen sorption analysis. Obtained results suggest good compatibility and correctness of SAXS data reading of nanocomposite systems and can be successfully applied for quick, nondestructive, and effective evaluation of structural properties of complex systems.

\section{GRAPHICAL ABSTRACT}

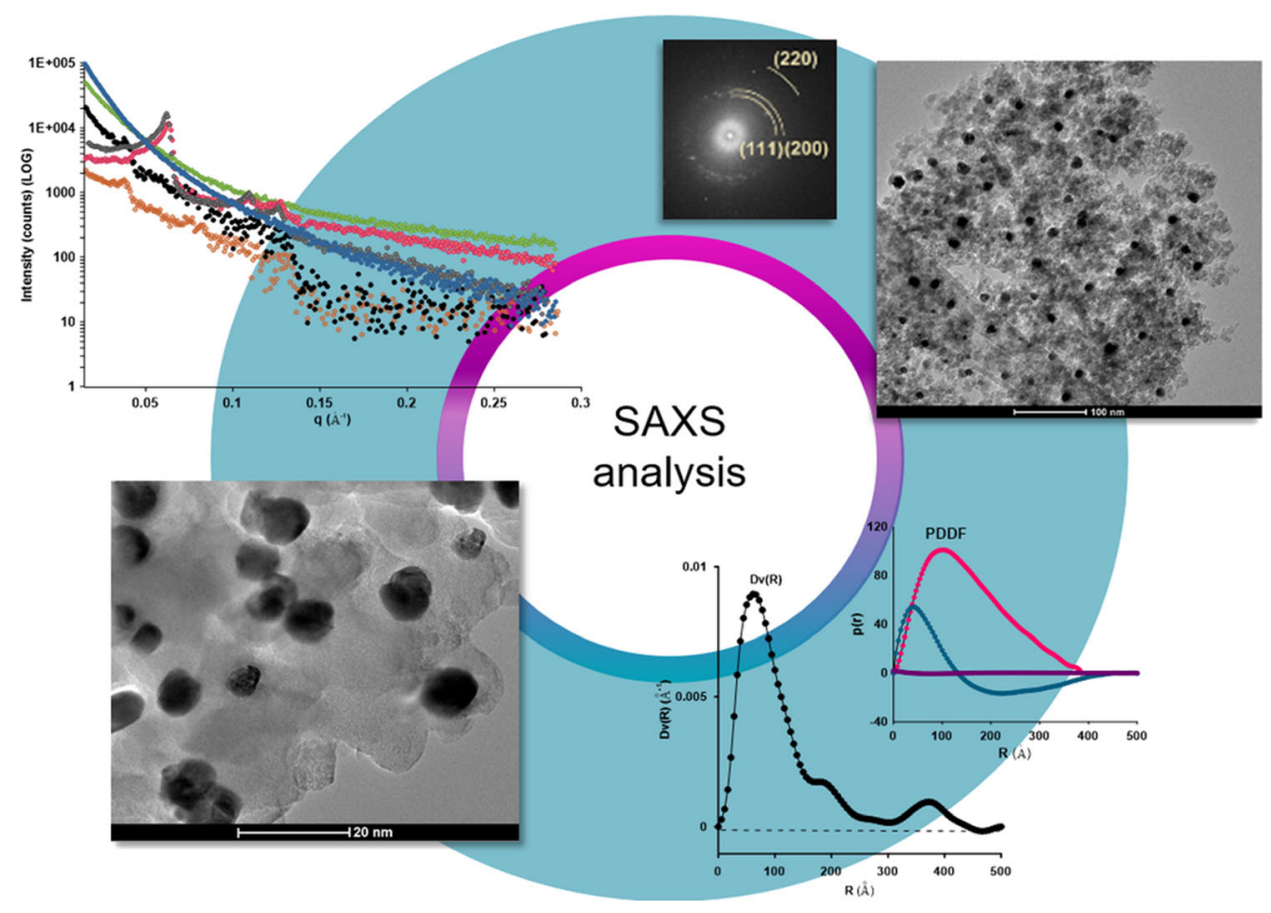

\section{Introduction}

Nanocomposite materials have become a great part of nanotechnology, their history, civilization importance, and condition for further technological progress. Biocomposites, nanocomposites, and bionanocomposites create a new generation of multielement materials with still growing potential of the application [1-4]. Nanocomposites constitute nanotechnology products with a constantly growing importance, mainly due to the ability to combine exceptional properties of general components [5, 6]. The significance of nanocomposite materials is apparent from the current formation of the integral part of nanomaterials with multifunctional properties. Likewise, the idea of combining organic or inorganic matrixes with metallic nanoparticles becomes an important part of material science [7, 8]. As a result of the progressive development, various types of inorganic nanostructured materials have been designed and produced to reinforce crucial properties such as optical (plasmonic) [9-12], magnetic [13-15], sensing, and biosensing [16-18]. A lot of effort is given to the development of sustainable and environmentally friendly methods of their preparation, characterization, as well as further processing $[19,20]$. In this field, the nanoparticles coupled with the inorganic or polymer structure can act as nanofiller with a high degree of dispersion as well as 
biocidal activity simultaneously [21, 22]. The introduction of metallic nanoparticles can be a way to improve the hydrophobicity, energy efficiency, or biocompatibility of the resulting systems. Moreover, the adaptability to the strength and durability of nanocomposites, which are directly related to the limited growth of various microorganisms can be preserved [23-25]. This is important in the production of packaging and protective materials in agricultural and medical applications [26-28].

The bulk properties of nanocomposite materials can be determined by their nanoscale features and described by structure-sensitive techniques (for example by the techniques of small-angle scattering of X-rays). The investigation of the structural and interfacial properties by SAXS can be applied for various types of functional hybrid materials. So far, the SAXS technique was satisfactorily applied for the investigation of the oriented lamellar nanocomposites formed of alternating organic and inorganic layers [29]. The average lamellar and amorphous, layer thicknesses can be determined using a combination of real-time small-angle $X$-ray scattering for sufficient characteristics of the system for engineering purposes [30]. Thermoplastic nanocomposites with silica nanoparticles [31], organic-inorganic nanocomposites based on epoxy resin, siloxane, acrylic, and poly(methyl methacrylate) networks [32] as well as silicon nanoparticles in various polymeric binders [33] and graphene/polymer nanocomposites [34] were also interesting research subjects. In most cases, the structural information relates to the radius of gyration $\left(R_{\mathrm{g}}\right)$ and aggregate size (Guinier's analysis), fractal type (Porod's law), and diffusion of interfacial regions. There are many efforts to investigate the properties and changes of the subtle microstructure of nanocomposites based on colloids and polymers as the nanocomposite building blocks and organo-clay nanocomposites [35-37]. The sensing and catalytic potential of these polymer-noble metal nanocomposites determine the investigation of particle size distributions and observations of small changes that cannot always be picked up by electron microscopy (TEM) [38]. In thematically related works, the authors often emphasize the assets of SAXS as a nondestructive way for analyzing the time evolution and characterizing some dynamic aspects of nanoparticles also in a wet state which cannot be accomplished using typical TEM [39]. Moreover, in-depth structural characterization of the nanocomposites can be applied to various materials of practical importance. Some works in this field suggest that the indication of the possible mechanism of nucleation during nanoparticle formation allows controlling their final morphology [40]. In other work, the unique capabilities of X-ray scattering were applied for structural characterization of materials in their native environment (in real time and under realistic sample environments) [41]. SAXS data can be applied also to study the conformation of the globular structure of bioactive materials such as dendrimers [42]. In this case, the combination of the radii of gyration $\left(R_{\mathrm{g}}\right)$, the maximum size of the particles $D_{\max }$ as well as the bell shapes of distance distribution functions $p(r)$ allows evaluating the spherical form of hybrid polycarbosilane-siloxane structures. It was found that the morphological changes in the nanocomposites made of polypropylene (PP) and multiwall carbon nanotubes (MWCNT) and modified montmorillonite (m-MMT) can be also monitored by SAXS and WAXS [43]. The comprehensiveness of the SAXS analysis for structural investigation has also been appreciated in the research of biological macromolecules and advanced biological systems [44] represented by RNA and proteins $[45,46]$. The specific application of the SAXS includes also in situ studies for monitoring the structural changes of polymer nanocomposites upon heating in battery systems [47] and pore dynamics in ordered mesoporous electrode materials [48-50]. Another example concerns biopolymer (cellulose) nanofibrils reinforced with nanoscopic latex particles analyzed by SAXS with both ex situ and in situ (synchrotron beamline) analysis [51- 53]. The SAXS data provide structural information about the fillers before and during strain measurements. Presented examples are not exhaustive but draw a SAXS analysis as a great tool for supporting the exploration of functional systems with nanodimensional features. The description of the SAXS theory and methodological aspects with the potential of the SAXS technique was presented in supplementary materials of this work (SI file, Fig. 1_SI, Fig. 2_SI).

In this paper, we highlight the fabrication and structural characteristics of nanocomposite materials constituting plasmonic metal nanoparticles (AgNP and AuNP) dispersed on selected types of nanostructured solid hosts with various physicochemical properties. An attempt was made to read the structural properties of various types of solid systems that are linked by the modifier type in the form of 
plasmonic nanometals. SAXS data were correlated with other dedicated research techniques and the accumulated results prove the value of the selected methodology in the field of nanostructured materials.

\section{Materials and procedures}

\section{Materials and chemicals}

Chitosan (MW 110,000; degree of deacetylation $0.74) \geq 75-85 \% \quad$ deacetylated and $99.9 \%$ tetraethoxysilane (TEOS) were provided by from Sigma-Aldrich. Silver nitrate $\left(\mathrm{AgNO}_{3}\right.$, ACS reagent, $\geq 99.0 \%$ ), trisodium citrate, gold(III) chloride solution $(99.9 \%$ trace metals basis, $30 \mathrm{wt}$.\% in dilute $\mathrm{HCl})$, Polyvinylpyrrolidone (PVP) (MW 10,000), and sodium borohydride $\left(\mathrm{NaBH}_{4}\right)$ were all purchased also from Sigma-Aldrich and used as a polymeric stabilizer, noble metal nanoparticles, noble metal precursors and reductant of nanoparticle precursors, respectively. Aqueous acetic acid ( $\geq 99.7 \%)$, ethanol, and concentrated hydrochloric acid were obtained from POCH (Avantor Performance Materials Poland S.A). All solutions were prepared with miliQ standard water. All reagents were used as supplied, without any further purification.

Chitosan support in the form of thin chitosan/silica composite film was obtained by the sol-gel method through hydrolysis of TEOS in the chitosan solution. Hydrophilic fumed silica (pyrogenic silica) in powder form with the average particle size of $0.2-0.4 \mu \mathrm{m}$ and amorphous structure (confirmed by the absence of lines in its X-ray diffraction patterns) was applied as support and purchased from Sigma-Aldrich. The specific surface area of the silica scaffold was determined by specific calculation (BET) using low-temperature nitrogen adsorption/desorption analysis as $S_{\text {BET }} \sim 200 \mathrm{~m}^{2} / \mathrm{g}$ and marked as relatively low porous material. The highly porous activated carbon marked as RIAA (Norit n.v., Amersfoort, Netherlands) was applied as a carbon carrier material for carbon/silver nanocomposite. Before use, the carbon reinforcement was degassed. for $24 \mathrm{~h}$ at $120^{\circ} \mathrm{C}$ in a vacuum, The specific surface area and total pore volume of the unmodified carbon adsorbent were determined as $1400 \mathrm{~m}^{2} / \mathrm{g}$ and $0.80 \mathrm{~cm}^{3} / \mathrm{g}$, respectively, according to the nitrogen amount adsorbed at a relative pressure $P / P_{0}$ of 0.99 . Activated carbon RIAA was found to be a highly microporous material where more than half of the pores fall on micropores. Mesoporous ordered silica scaffold was prepared by the typical procedure of organic template dissolving in acidic solution followed by the addition of silica source.

\section{Synthesis of noble metal colloidal solutions and related nanocomposites}

Colloidal silver solution was obtained by reduction of $\left[\mathrm{Ag}\left(\mathrm{NH}_{3}\right)_{2}\right]^{+}$(diamminesilver(I) complex). In this procedure, the silver(I) oxide obtained firstly by precipitation silver ions from silver nitrate $(0.3 \mathrm{M})$ by sodium hydroxide $(1.25 \mathrm{M})$ was dissolved until the complete absence of precipitates using concentrated (25\%) ammonium hydroxide $(2.63 \mathrm{ml})$. The chemical reactions and details of the synthesis diamminesilver(I) complex were described in detail in our previous work [54]. The AuNP colloidal solution was prepared by reduction of tetrachloroauric acid $\left(\mathrm{HAuCl}_{4}\right)$ with trisodium citrate and $\mathrm{NaBH}_{4}\left(\mathrm{Na}_{3} \mathrm{Ct}\right)$ at $100{ }^{\circ} \mathrm{C}$ in the presence of PVP as a stabilizer agent. Freshly prepared silver precursor in the form of $\left[\mathrm{Ag}\left(\mathrm{NH}_{3}\right)_{2}\right]^{+}$was used for direct adsorption of silver ions on the solid surface of low-porous silica, carbon, and chitosan supports and marked as NAgNP, CAgNP, and CsAgNP nanocomposites, respectively. In particular, $1 \mathrm{~g}$ of suitable support material was immersed in a $50 \mathrm{~mL}$ solution containing noble metal precursor. Next, ammonia in quantities of several drops, the stabilizer solution $(5 \mathrm{ml}$ of $5 \%$ PVP solution), $45 \mathrm{~mL}$ of distilled water, and $0.2 \mathrm{~mL}$ of $\mathrm{Ag}\left[\left(\mathrm{NH}_{3}\right)_{2}\right]^{+}$were added to the entire. Mixtures were stirred for $4 \mathrm{~h}$ at room temperature in a dark place. Then small amount (several milligrams) of $\mathrm{NaBH}_{4}$ was added to the mixtures. After $2 \mathrm{~h}$, nanocomposites were washed using distilled water to remove the residues and dried overnight at $40{ }^{\circ} \mathrm{C}$ under a vacuum. The reduced form of gold nanoparticles was affixed on the chitosan biopolymer surface via deposition from the liquid phase by immersing solid chitosan material to the red solution of as-prepared AuNP for obtaining CsAuNP. Further, the silver phase was deposited on a mesoporous ordered silica surface $\mathbf{M S i O}_{2}$ for obtaining $\mathbf{M S i O}_{2} \mathbf{A g N P}$ nanocomposite. More specifically, a colloidal silver solution was prepared by chemical reduction of a $\left[\mathrm{Ag}\left(\mathrm{NH}_{3}\right)_{2}\right]^{+}$solution using a suitable reducing agent (formaldehyde) according to Tollens procedure guidelines. The stabilization of the silver 
nanoparticles was necessary to make a stable and useful noble metal modifier. This stage was carried out by applying the PVP polymer solution as a reaction medium. On account of the reduction of silver ions, a yellow-orange solution of colloidal silver was obtained. The spectral characteristic of the colloidal silver solution in their qualitative control was involved. A sample was marked as CsAgNP based on chitosan/silica thin film obtained by the sol-gel procedure. Here, TEOS $(5 \mathrm{~mL})$, as a silica source, was added to a solution containing $50 \mathrm{ml}$ of ethanol, $1 \mathrm{~mL}$ of concentrated hydrochloric acid, and $10 \mathrm{~mL}$ of distilled water. Throughout, the stirring by $30 \mathrm{~min}$, this solution was slowly dropwise to the chitosan solution ( $1 \mathrm{~g}$ of chitosan dissolved in $100 \mathrm{ml}$ of $1 \%$ acetic acid). Stirring was continued for $24 \mathrm{~h}$. Finally, the obtained nanocomposite was positioned on a flat level and dried at $50{ }^{\circ} \mathrm{C}$ by $24 \mathrm{~h}$ and finally at $80^{\circ} \mathrm{C}$ by the next day. Mesoporous silica material was prepared by dissolving the nonionic polymer Pluronic P123 into the solution of $50 \mathrm{~mL}$ deionized water and $120 \mathrm{~mL}$ of $2 \mathrm{M} \mathrm{HCl}$ in the first stage. Next, $9.12 \mathrm{~g}$ of tetraethyl orthosilicate was slowly added to the first mixture. The synthesis solution was maintained at $35{ }^{\circ} \mathrm{C}$ for $24 \mathrm{~h}$ under stirring and heated at static conditions at $95^{\circ} \mathrm{C}$ for the next $48 \mathrm{~h}$. After synthesis and separation of the white product from solution, the polymeric template was removed by high-temperature treatment at $550{ }^{\circ} \mathrm{C}$ for $4 \mathrm{~h}$ with a $3{ }^{\circ} \mathrm{C} / \mathrm{min}$ heating rate in a muffle furnace under an air atmosphere.

\section{Measurements and calculations}

The SAXS analysis was carried out by X-ray diffraction (XRD) using an Empyrean diffractometer (PANalytical) with $\mathrm{CuK} \alpha$ radiation using the SAXS/ WAXS stage and capillary mode. The SAXS configuration includes a $2 \theta$ range of $0.13-4$ degrees of $2 \theta$. The device was powered by a $4 \mathrm{~kW}$ high-voltage $X$-ray generator and generator settings of $40 \mathrm{kV}$ and $40 \mathrm{~mA}$, and reflection geometry was applied during measurements. The measurement was taken in a single-scan mode. The incident beam path consisted of a line focus type, $\mathrm{W} / \mathrm{Si}$, graded X-ray mirror with elliptic shape. The primary beam was measured using beam attenuator $\mathrm{Cu} 0.2 \mathrm{~mm}$. The measurements were taken using a PIXcel1D detector, and receiving slit with $0.05 \mathrm{~mm}$ active length. The length of the scattering vector (or scattering vector) $\mathrm{q}$ is defined as $q=4 \pi \sin \theta / \lambda$, where $2 \theta$ the scattering angle, $\lambda$ is the $X$-ray wavelength (1.5418 $\AA$ ). The corresponding range of $q$ values over which the measurement was taken was 0.0095-0.28 $\AA^{-1}$. Background scattering was performed by air scattering measure with an empty sample holder. The measurement times were the $2300 \mathrm{~s}$ for each sample. $\operatorname{Dv}(R)$ calculations were performed using the indirect Fourier transformation technique applied in EasySAXS software. In this case, the applied algorithm is based on Tikhonov's regularization method [55]. Pair distance distribution function (PDDF) as real space counterparts of the experimental intensity $(p(r))$ was calculated by the EasySAXS program as an indirect Fourier transform of these data. The Guinier plot as $\ln (I(q))$ vs. $q^{2}$ was used to determine the radius of gyration $R_{\mathrm{g}}$ from the slope of the plot $\left(-R_{\mathrm{g}}{ }^{2} / 3\right)$. Evaluation of the porosity of the silica samples was performed using a low-temperature isothermal nitrogen adsorption-desorption using an automatic Micromeritics ASAP2020 device. Specific surface areas were computed from experimental isotherms by applying the BET theory and linear range of the BET plot [56]. All samples were degassed before analysis for $24 \mathrm{~h}$ in degas port of analyzer. Scanning electron micrographs were collected from Quanta 3D FEG (FEI). Transmission electron microscopy (Tecnai G2 T20 X-TWIN) was used to record AgNP size and morphology after their extraction from the solid phase. For this study, the samples were prepared by placing a drop of NP extracted from the suitable nanocomposite onto a carbon-coated copper grid, dried in the air, and then transferring the grid to the microscope operated at an accelerated voltage of $200 \mathrm{kV}$.

\section{Results and discussion}

\section{Starting materials_characterization}

As the initial step of the investigation, the colloidal reference materials (AgNP and AuNP colloidal solutions) were examined by SAXS, TEM, and UVVis (Fig. 1). The SAXS profiles of Ag and Au colloidal precursors reveal the oscillations in the $\mathrm{q}$ region above 0.05. For both cases (Fig. 1a, b), the form oscillation in the $q$ region was similar suggesting the comparable size of Ag and Au nanoparticles. Particle size distributions $(\operatorname{Dv}(R))$ were determined by using 
(a)

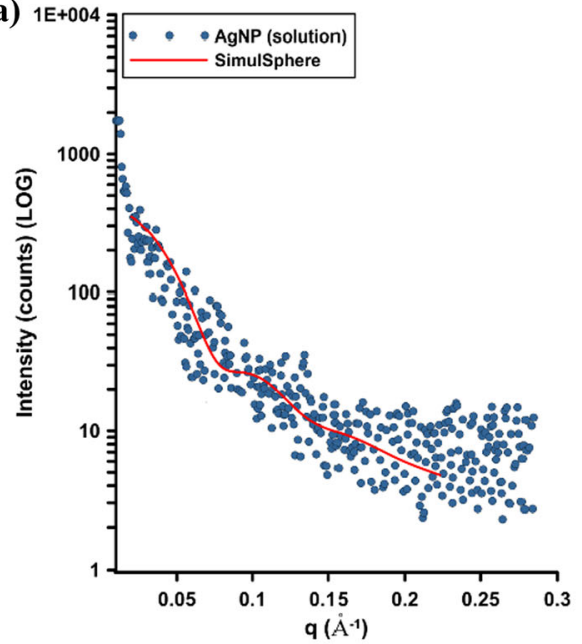

(c)

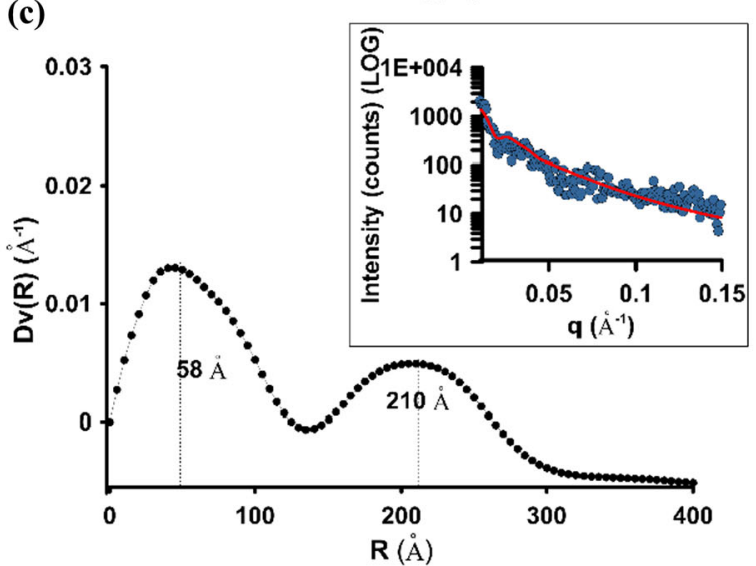

(e)
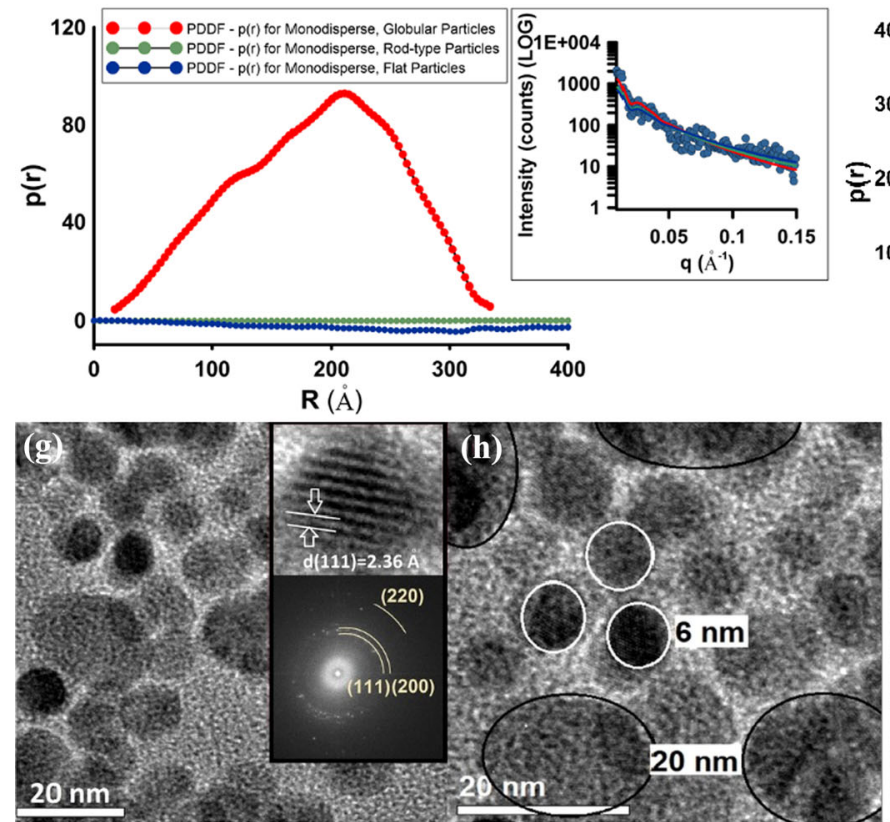

(b)

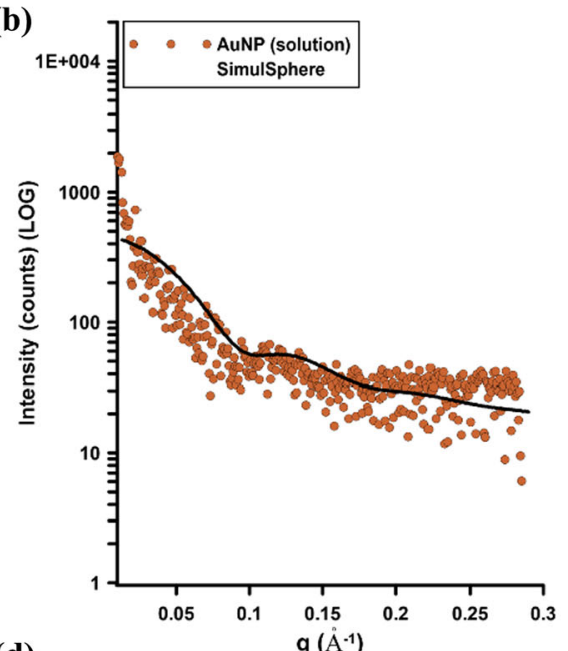

(d)

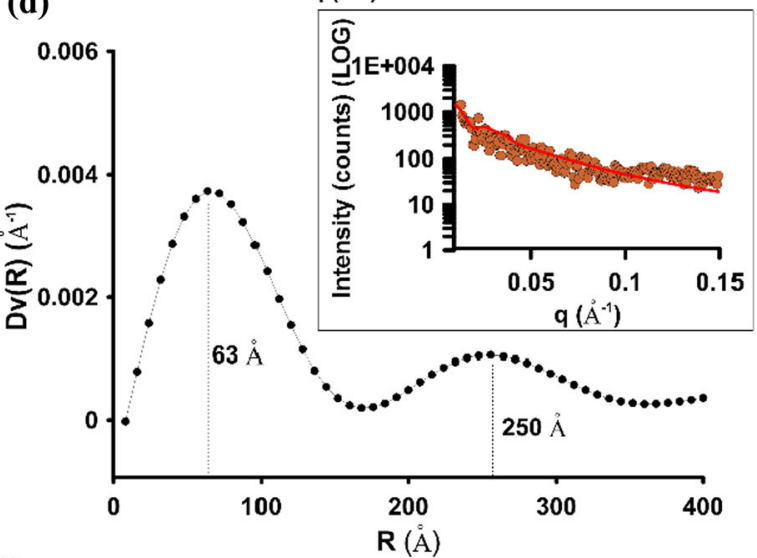

(f)
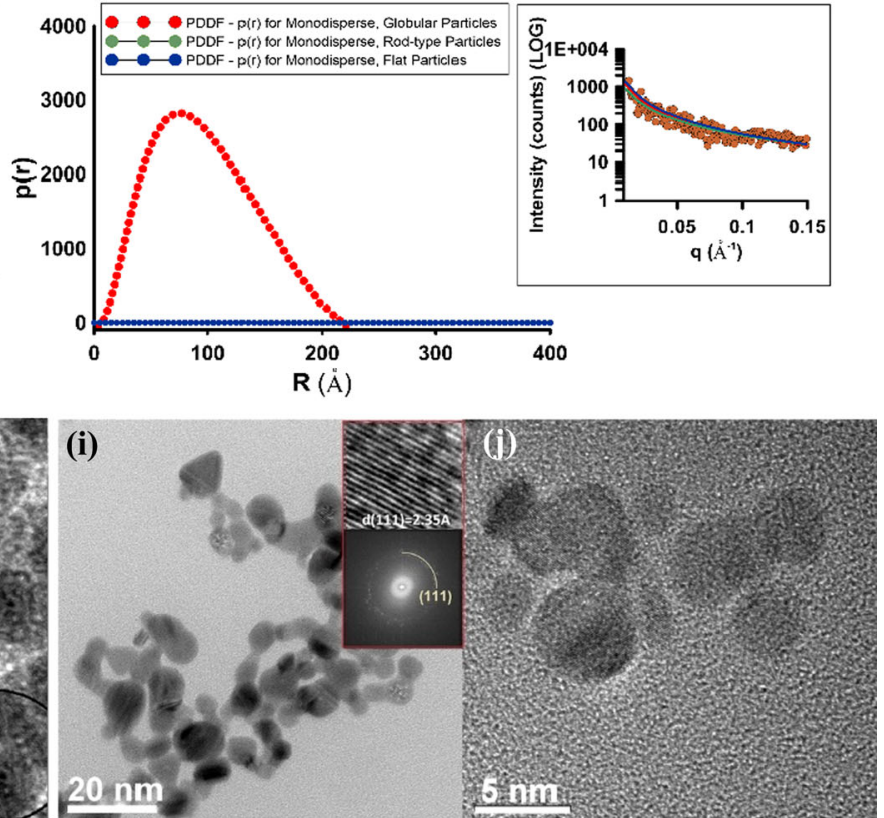
4 Figure 1 SAXS and TEM investigation of initial colloidal solutions. a SAXS profile including the background-corrected data of AgNP, $\mathbf{b}$ SAXS profile of AuNP, $\mathbf{c}$ the particle size distribution $(\operatorname{Dv}(R))$ of $\mathrm{AgNP}$, and fitting the calculated model to experimental points as inset, $\mathbf{d}$ the particle size distribution $(\operatorname{Dv}(R))$ of AuNP with fitting as an inset. In insets, dots represent the experimentally obtained SAXS profile. The solid curve is the calculated SAXS profile. e Pair distance distribution functions (PDDFs) of as-prepared AgNP and AuNP $\mathbf{f}$ with fitting curves as insets. $\mathbf{g}, \mathbf{h}$ TEM images of AgNP colloidal solution (inset presents HRTEM micrograph of one selected particle for defining fringes of first Ag crystal lattice and FFT image of the selected area of the TEM image), $\mathbf{i}, \mathbf{j}$ TEM images of AuNP colloidal solution with HRTEM of selected Au particle and FFT image as insets.

the indirect Fourier transformation procedure establishing a spherical particle morphology for both types of nanoparticles (Fig. 1c, d). SAXS analysis showed a bimodal scatterer size distribution for $\mathrm{Ag}$ and $\mathrm{Au}$ nanoparticles. The average particle size of bimodal distribution was determined as $58 \AA$ and $210 \AA$ for Ag nanoparticles, and $63 \AA$ and $250 \AA$ for $A u$ nanoparticles, respectively. The PDDF calculations exhibit a characteristic curve with PDDF signal at $\sim 200 \AA$ and $95 \AA$ for AgNP and AuNP, respectively (Fig. 1e, f). Based on $\operatorname{Dv}(\mathrm{R})$ and PDDF parameters, it is expected that the spherical shape of particles should be assumed for both cases. The particle sizes obtained by SAXS agree with the results from transmission electron microscopy in general; however, it is worth reinforcing that SAXS results can be more statistically average than electron microscopic techniques. The TEM micrographs show the bimodal distribution of the AgNP with the size determined as $60 \AA$ and further $200 \AA$ (Fig. 1g, h). The size of AuNP below $100 \AA$, as well as some part of greater diameters $(\sim 200 \AA)$, was also confirmed (Fig. 1i, j). Two types of nanoparticles in the investigated systems suggest the dynamic state of the colloidal solution and may imply still ongoing crystal growth. TEM images suggest also significant polydispersity of nanoparticles due to the presence of several crystallites or domains within nanoparticles. A similar effect was observed and discussed in other works and confirms the correct behavior of the nanoparticle system [57]. Furthermore, the size polydispersity (given by the ratio of the standard deviation of the size distribution to the average radius) from SAXS calculations was determined to be 9.8\% and $10 \%$ for $\mathrm{Ag}$ and $\mathrm{Au}$ nanosystems.

The spectroscopic quality of the colloidal systems was also satisfactory. The initial colloid solutions were active in the electromagnetic field revealing a clear plasmonic response. UV-Vis spectra of as-prepared colloidal silver and gold nanoparticles were determined as a plasmonic fingerprint of investigated nanosystems (surface plasmon resonance band at $420 \mathrm{~nm}$ and $550 \mathrm{~nm}$ appeared for AgNP and AuNPs, respectively) and are presented in SI file (Fig. 3_SI). The characteristic resonance bands of oscillation frequency appear in the visible region for gold and silver giving rise to the strong surface plasmon resonance absorption and confirming their correct morphology.

The initial analysis of precursors indicates the synthesis of well-dispersed colloid solutions described as consisting of two major populations of small $(\sim 60 \AA)$ and larger nanoparticles with a diameter from 200 to $300 \AA$. Good quality of the metallic nanoparticles was revealed by suitable crystal structure disclosed by HRTEM images. Properties of initial precursors at this stage allow their effective use in further experimental steps. Their stability and initial forms were appropriate for subsequent processing and binding with the solid matrixes with different physicochemical properties.

\section{Nanocomposites-morphology analysis}

A survey of nanocomposite materials requires the analysis of structural aspects that determine their usefulness and chance for future applications. The nanocomposite systems of inorganic silica, biopolymer, and carbon matrices modified and nanostructured metallic phases (silver and gold) were investigated by evaluating the particle size distribution, their preferred shape, and possible interaction, as well as their stability on selected support materials with diverse physicochemical and structural properties. Table 1 summarizes the investigated nanocomposite materials as well as sums up the most important microstructure parameters.

All the considered systems are capable of scattering X-rays in the range of low angles. Some differentiation of the scattering effect was observed depending on the tested system in terms of scattering intensity and curvature of scattering profile as well as the presence of characteristic peaks. Figure 2 shows 
Table 1 Description and structural parameters of the investigated systems

\begin{tabular}{|c|c|c|c|c|c|c|c|c|c|c|c|c|}
\hline \multirow[t]{2}{*}{ Sample } & \multirow[t]{2}{*}{$\begin{array}{l}\text { Short } \\
\text { description }\end{array}$} & \multirow{2}{*}{$\begin{array}{l}\text { Dv } \\
(R)^{\mathrm{a}} \\
{[\AA]}\end{array}$} & \multirow[t]{2}{*}{$\begin{array}{l}\mathrm{PDDF}^{\mathrm{b}} \\
{[\AA]}\end{array}$} & \multirow{2}{*}{$\begin{array}{l}D_{\max } \\
(\mathrm{PDDF})^{\mathrm{c}} \\
{[\AA]}\end{array}$} & \multicolumn{2}{|l|}{$\begin{array}{l}R_{\mathrm{g}} \\
[\AA]]\end{array}$} & \multicolumn{4}{|c|}{$\begin{array}{l}\text { Porod } \\
\text { approximation }\end{array}$} & \multicolumn{2}{|c|}{$\begin{array}{l}\text { Specific surfaces } \\
\text { area }\end{array}$} \\
\hline & & & & & $\mathrm{PDDF}^{\mathrm{f}}$ & Guinier $^{\mathrm{g}}$ & $\mathrm{K}_{\mathrm{P}}^{\mathrm{h}}$ & $\begin{array}{l}Q^{\mathrm{i}} \\
{\left[\AA^{-1}\right]}\end{array}$ & $\mathrm{C}_{0}{ }^{\mathrm{j}}$ & $\begin{array}{l}S / V \\
{\left[\AA^{-1}\right]}\end{array}$ & $\begin{array}{l}S_{\mathrm{SAXS}}{ }^{\mathrm{k}} \\
{\left[\mathrm{m}^{2} / \mathrm{g}\right]}\end{array}$ & $\begin{array}{l}S_{\text {BET ADS }} \\
\text { DES } \\
{\left[\mathrm{m}^{2} / \mathrm{g}\right]}\end{array}$ \\
\hline NAgNP & $\begin{array}{l}\text { Nonporous } \\
\text { silica matrix } \\
\text { with AgNP }\end{array}$ & 61 & 100 & 385 & $111^{\mathrm{e}}$ & 107 & 0.605 & 54.50 & -10.1 & 0.044 & 202 & 200 \\
\hline CsAgNP & $\begin{array}{l}\text { Chitosan film } \\
\text { with AgNP }\end{array}$ & $\begin{array}{l}25 \\
(75)\end{array}$ & $28(70)$ & 133 & 48 & 66 & 0.511 & 17.43 & -35.4 & 0.011 & 73 & 89 \\
\hline CsAuNP & $\begin{array}{l}\text { Chitosan film } \\
\text { with AuNP }\end{array}$ & 60 & 45 & 143 & 47 & 60 & 0.410 & 15.49 & -52.4 & 0.01 & 70 & 74 \\
\hline CAgNP & $\begin{array}{l}\text { Microporous } \\
\text { carbon with } \\
\text { AgNP }\end{array}$ & 46 & 67 & 340 & 108 & 101 & 1.277 & 47.23 & 114.0 & 0.107 & 2000 & 1468 \\
\hline $\mathrm{MSiO}_{2}$ & $\begin{array}{l}\text { Mesoporous } \\
\text { hexagonal } \\
\text { ordered } \\
\text { silica }\end{array}$ & 50 & 36 & 71 & 24 & 44 & 1.336 & 25.46 & 28.1 & 0.209 & 950 & 798 \\
\hline $\mathrm{MSiO}_{2} \_\mathrm{AgNP}$ & $\begin{array}{l}\text { Mesoporous } \\
\text { hexagonal } \\
\text { ordered } \\
\text { silica with } \\
\text { AgNP }\end{array}$ & $\begin{array}{l}250 \\
(400)\end{array}$ & 180 & 400 & 139 & 133 & 0.544 & 16.16 & 2.2 & 0.134 & 613 & 573 \\
\hline
\end{tabular}

${ }^{\mathrm{a}}$ The volume-weighted particle size distribution $\mathrm{Dv}(\mathrm{R})$ as the maximum value of the function

${ }^{\mathrm{b}}$ Pair distance distribution function (PDDF) as the maximum value of the function (marked sometimes as $R$ or $r_{\max }$ )

${ }^{\mathrm{c}}$ Maximum dimension $D_{\max }$ means also $R$-value (distance) at which PDDF goes to 0 . This parameter is defined as diameter across the longest dimension of the particles and is zero for $r>D_{\max }$

${ }^{\mathrm{d}}$ Radius of gyration as the mean square distance from the center of their distribution. Rg provides a measure of the overall size of the scattering objects

${ }^{\mathrm{e}}$ For the NAgNP sample, the radius of gyration of the cross section was also determined: $R_{\mathrm{c}}=257 \AA$

${ }^{\mathrm{f}} R_{\mathrm{g}}$ determined from $p(r)$ function is proportional to the normalized second moment of $p(r)$ (Eq. 4 ) from the whole scattering curve ${ }^{\mathrm{g}}$ The Guinier plot, as $\ln (I(q))$ vs. $q^{2}$ was used to determine the $R_{\mathrm{g}}$ from the slope of the Guinier plot

${ }^{\mathrm{h}}$ Porod constant is proportional to the surface area and the square of the electron density contrast

${ }^{i}$ Scattering invariant $Q$ is proportional to the mean-square density fluctuation of scattering volume. $Q=2 \pi^{2} \cdot \Delta \rho^{2} \cdot V$ where volume $V$ and scattering contrast $\Delta \rho$. For calculation $Q$ invariant the scattering intensities to $q=0$ and also toward large $q$ should be extrapolated

${ }^{\mathrm{j}}$ Bacground constant which illustrates asymptotic decay of the SAXS curve at the high $q$ values

${ }^{\mathrm{k}}$ Surface area by SAXS calculated by Eq. 8 (SI)

the experimental scattering data recorded for considered systems. The highest scattering intensity suggests large dimensions of scattering objects due to the larger electronic density of the dispersed phase, as well as the highest concentration of scatterers in the whole sample. The highest level of scattering intensity in the initial range of the curve $(q<0.043 \AA)$ was achieved for low-porous silica modified by AgNP (NAgNP). However, at a point of $q \sim 0.043 \AA$, the trend is reversing toward carbon/silver nanoparticles (CAgNP). Accordingly, AgNP nanoparticles with diameters $\sim 100-150 \AA$ can be responsible for the SAXS effect in NAgNP nanocomposite. (The values of the sizes of electron 
(a)

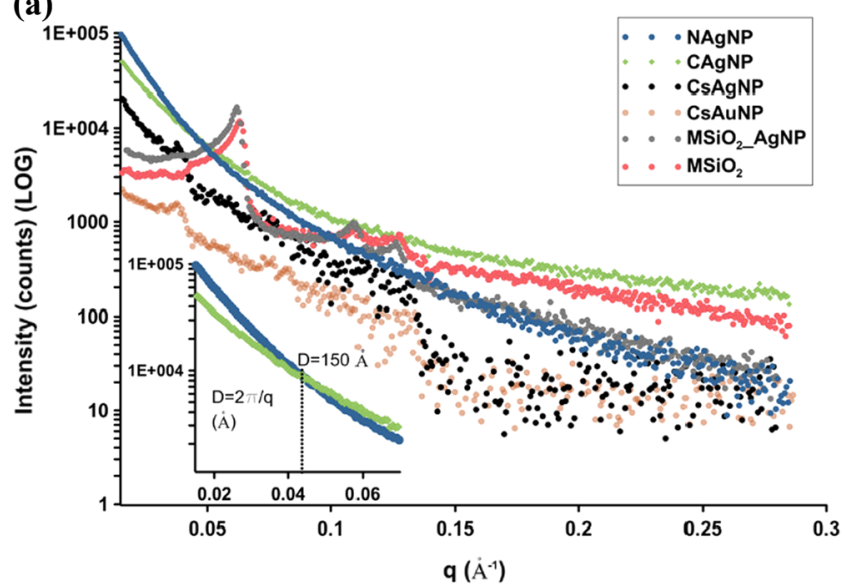

Figure 2 Experimental SAXS curves of investigated materials: NAgNP, CAgNP, CsAgNP, CsAuNP, $\mathrm{MSiO}_{2}$ and $\mathrm{MSiO}_{2} \mathrm{AgNP}_{\text {. }}$ The intensity versus momentum transfer $q$ (length of scattering vector) is plotted in $\log -\operatorname{linear}(\mathbf{a})$ and $\log -\log$ (b) plots. A clear

density inhomogeneity described as $d=2 \pi / q$ (where $q=2 \pi \sin \theta / \lambda$ ) were calculated as $150 \AA$ for $q=0.043 \AA$ and presented as an inset of Fig. 2a). Higher content of nanoparticles with smaller diameters is revealed for microporous activated carbon system (CAgNP) higher scattering intensity for the higher q values. The extensive microporous structure of CAgNP (higher scattering intensity above $0.043 \AA^{-1}$ ) may participate in the effective immobilization of nanoparticles with smaller sizes. The chemically rich surface of carbon matrixes equipped with various types of functional groups affect the deposition and stabilization of noble metal nanoparticles and influence their final form in such type of layout [58]. Scattering intensity was slightly lower for biopolymer nanocomposites (CsAgNP and CsAuNP). The lower scattering intensity can point to the presence of small clusters on the surface which can reduce the biopolymer-void electron contrast but are not large enough to build a biopolymer-metal layout with high electron contrast level. Further, the biopolymer nanocomposite modified by gold nanoparticles shows a weaker scattering effect than the silver counterpart, however, the course of scattering profiles for both samples was similar in general. In this case, it is expected a lower content of gold nanoparticles in the biopolymer system suggesting their impeded immobilization on the biopolymer surface without an additional chemical modification (e.g. by functional groups with high affinity to $\mathrm{Au}$ molecules [59]). SAXS patterns of unloaded

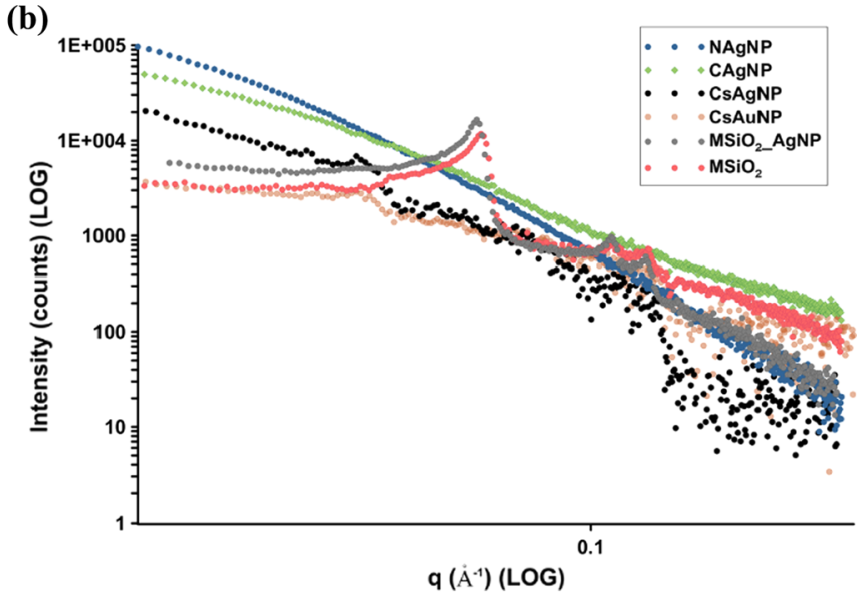

jump in intensity for CsAgNP and CSAuNP nanocomposites ( $q \sim 0.14 \AA^{-1}$ ) was associated with exceeding the thickness of the composite film layer and further scattering effect makes no analytical sense.

mesoporous silica $\left(\mathrm{MSiO}_{2}\right)$ material as well as mesoporous silica modified by $\mathrm{AgNP}\left(\mathrm{MSiO}_{2} \mathrm{AgNP}\right)$ exhibit scattering peaks characteristic of an ordered two-dimensional hexagonal mesostructure with the p6mm symmetry. The general shape of scattering profiles, as well as scattering intensity of (100), (110), and (200), peaks slightly changed after AgNP incorporation. The higher intensity in their initial range and their further decrease in the tail section demonstrate the presence of AgNP on the mesoporous silica surface and may be related to the reduction of the available porous space by noble metal nanoparticles. The important research in the analysis of the smallangle scattering patterns from hierarchical materials loaded by metallic phase can be correlated [60].

Figure 3 shows the volume-weighted particle size distribution $\operatorname{Dv}(R)$ from the scattering curve of an ensemble of spherical scattering objects. $\mathrm{Dv}(\mathrm{R})$ function of nonporous silica sample modified by AgNP (NAgNP, Fig. 3a) suggests the most frequent radius of particles as $61 \AA$, average radius as $113 \AA$, and the median particle radius as $86 \AA$. The most frequent radius of particles (as $61 \AA$ ) may indicate the size of basic clusters that build structures with larger sizes. Bimodal characteristic of $\operatorname{Dv}(\mathrm{R})$ function was observed for carbon-based nanocomposite (CAgNP) (Fig. 3e). In this case, the most frequent radius of particles was determined as $15 \AA$ and $46 \AA$, whereas the average particle radius and median radius was assigned as $49 \AA$ and $\sim 44 \AA$, respectively. The bimodal course of the $\operatorname{Dv}(R)$ function may be 

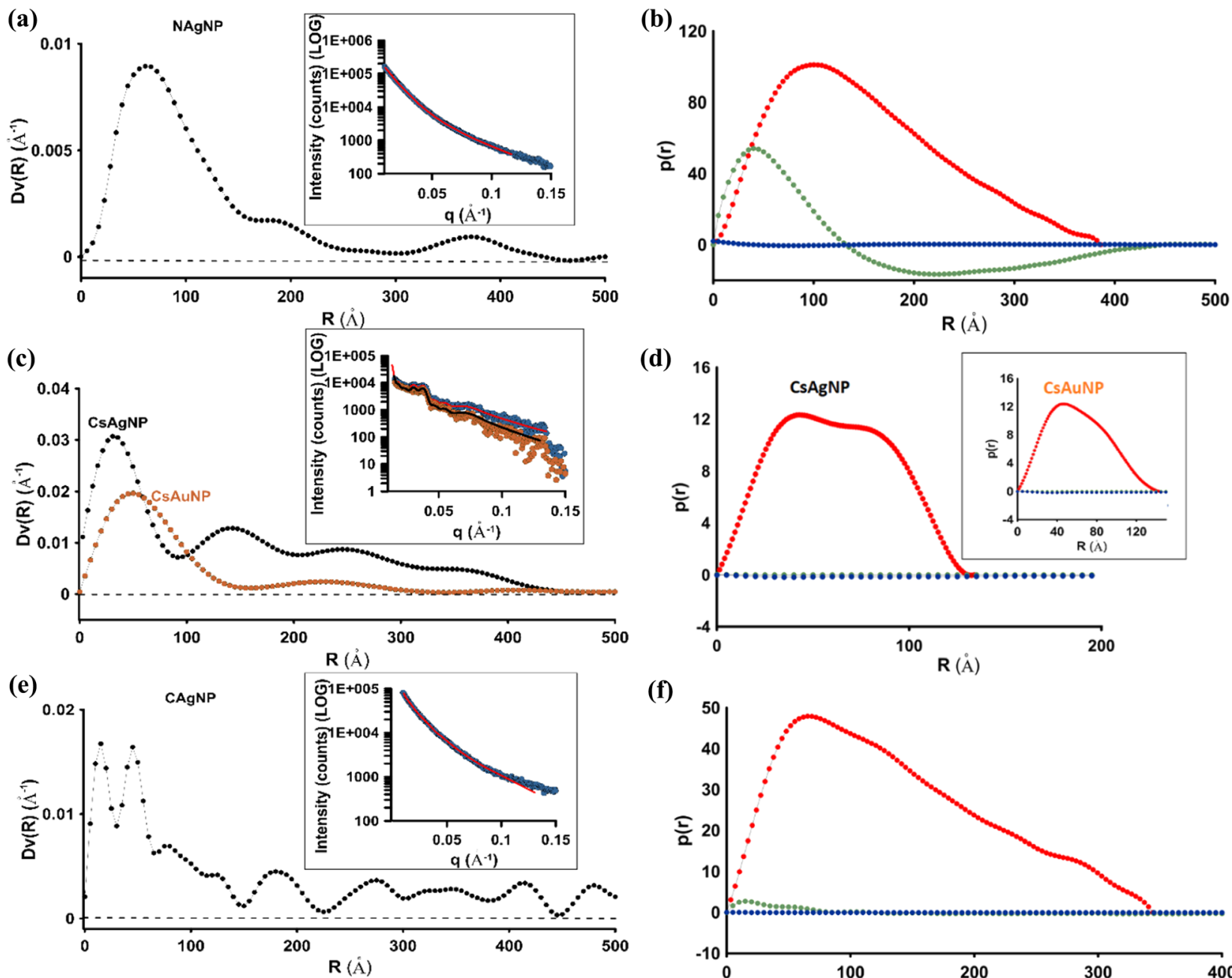

(f)
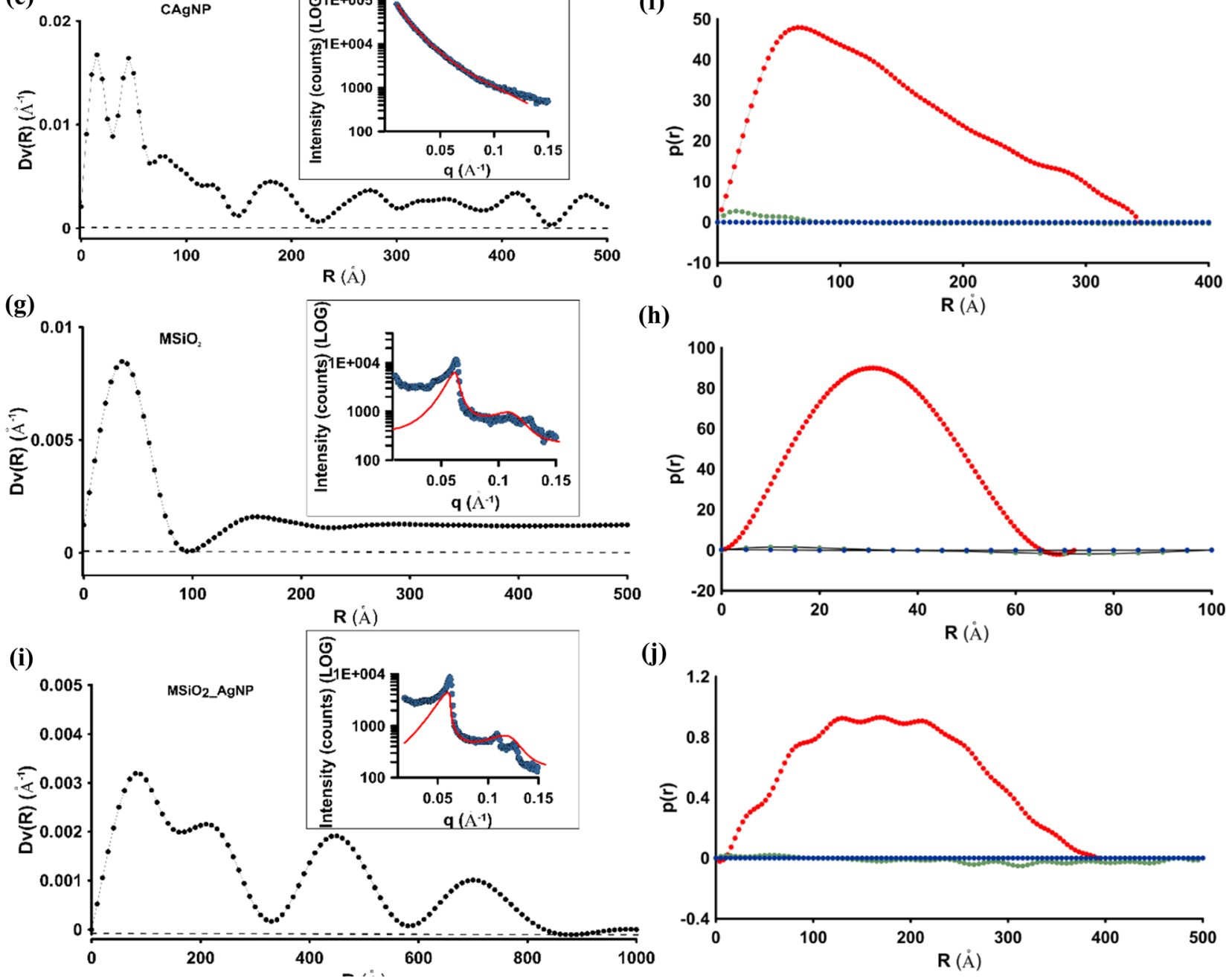
4 Figure 3 Particle size distribution by volume analysis for NAgNP (a), $\mathrm{CsAg} / \mathrm{AuNP}$ (c), $\mathrm{CAgNP}$ (e), $\mathrm{MSiO}_{2}$ (g) and $\mathrm{MSiO}_{2} \_\mathrm{AgNP}$ (i). The insets corresponding fit curves (solid lines) toward experimental data (points). The pair distance distribution functions (PDDFs) for investigation systems: NAgNP (b), CsAg/AuNP (d), $\mathrm{CAgNP}(\mathbf{f}), \mathrm{MSiO}_{2}$ (h) and $\mathrm{MSiO}_{2} \_\mathrm{AgNP}(\mathbf{j})$. The red points refer to monodispersed globular particle model, green points as monodispersed rod-type model and blue points as flat particle model. Standard deviation (RSD) during $\operatorname{Dv}(R)$ analysis was obtained as: $32.1 \%, 27.3 \%, 23.8 \%, 22.7 \%, 28.4 \%$, and $22.5 \%$.

associated both with the micropores of the carbon matrix ( $15 \AA$ ) and AgNP (46 $)$. What is important, the $\operatorname{Dv}(\mathrm{R})$ calculations suggest the presence of a significantly smaller (in size) population of AgNP than for silica nanocomposites (NAgNP). Such a significant reduction of the suggested diameters is also closely related to the preliminary observations from the course of the scattering curves and shows the possible clustering effect on the surface of the silica material leading to the formation of nanosized structures with slightly larger dimensions. Biopolymer systems exhibited even smaller diameters of the immobilized particles (especially CsAgNP sample). In this case, the most frequent radius of particles was determined as $25 \AA$ and the average radius, as well as a median particle, was determined as $23 \AA$. The $\operatorname{Dv}(\mathrm{R})$ function of CsAuNP shows slightly higher values ( $44 \AA, 49 \AA$, and $47 \AA$ for most frequent, average, and median radius, respectively) (Fig. 3 c). As regards the CsAgNP calculations, some oscillations of the $\operatorname{Dv}(\mathrm{R})$ function were obtained which may suggest the multimodal nature of the CsAgNP nanocomposite. A more monodisperse distribution of the size was obtained for the gold system (CsAuNP). However, in this case, one prominent peak is much more pronounced and may suggest a lower concentration of metallic phase on the biopolymer surface. The difference in concentration may indicate a lower affinity of gold nanoparticles to the polymer surface $[61,62]$. The existence of the ultra-small silver nanoparticles on functional biopolymer surfaces is typical and related to the presence of a large number of amino $\left(-\mathrm{NH}_{2}\right)$ and hydroxyl $(-\mathrm{OH})$ groups with chemical activity for even in situ reduction of silver precursor to nanometric form [63]. Multimodal characteristic of $\operatorname{Dv}(R)$ function was obtained both for mesoporous ordered silica materials and their AgNPmodified counterpart (Fig. $3 g$, i). The maximum function at $50 \AA$ can be correlated with the diameter of the pore system (the lattice plane of the hexagonal system was calculated and presented in SI). After immobilization of AgNP, the pore system was still visible; however, the additional peak at $\sim 250 \AA$ and $400 \AA$ correlated with the AgNP phase was also noticed.

Pair distance distribution functions (PDDFs) were calculated for several theoretical geometries of scattering objects: monodisperse globular particles, monodisperse rod-type particles, and monodisperse flat particles (Fig. 3b, d, f, h, and j). For spherical objects, the PDDF determines the maximum particle dimension $\left(D_{\max }\right)$ and illustrates the symmetry of particles (spherical morphology). In general, the scattering objects presented in this work indicate spherical or almost spherical symmetry. The most spherical particles were obtained for the $\mathrm{MSiO}_{2}$ sample which contains mesopores and micropores as a specific stiff template as a potential solid stabilizer of the nanoparticles. Spherical pores in $\mathrm{MSiO}_{2}$ were illustrated by PDDF as $36 \AA$ and $71 \AA$ for the most prominent pair distances and maximal dimensions, respectively (Fig. 3h). For noble metal-modified nanocomposites, the most spherical structures were obtained for CsAgNP (bimodal admittedly) (Fig. 3d).

A subtle deviation from the clear spherical shape was visible as dilatation from the ideal symmetric function and the presence of curve tail shifted to the higher $r$ values and confirmed for NAgNP (Fig. 3b) and CAgNP nanocomposites (Fig. 3f). The heterogeneity of the spherical shape by the perceptible PDDF of the cross section was also confirmed. The PDDF function suggests the mean distance of $100 \AA$ and $D_{\max } \sim 385 \AA$ as well as $67 \AA$ and as $340 \AA$ for NAgNP and CAgNP samples, respectively. Of course, the obtained results reflect the unique features of the AgNP stabilized on the solid surfaces, and it is important to be aware of the imperfect form system.

To clarify the data, the radius of gyration $\left(R_{\mathrm{g}}\right)$ parameter was determined from the pair distribution function as well as from Guinier approximation for spherical morphology. $R_{\mathrm{g}}$ is the average of square center-of-mass distances in the molecule (weighted by the scattering length density). The linear regions of the Guinier plot in the initial range of the $q$ vector reveal the presence of nanoparticles with spherical morphology. However, it should be noted that the linearity area of the Guinier curves was quite narrow, 
which may suggest the limited amount of spherical inhomogeneities due to possible aggregation and nanoparticle growth processes. (Guinier plots as $\ln (I(q))$ vs. $q^{2}$ are shown as Fig. 4 SI). The $\mathbf{R}_{\mathrm{g}}$ parameter determined by Guinier approximation was nearing the values determined from PDDF analysis (Table 1) and equals $107 \AA$, $101 \AA$, $66 \AA$, $60 \AA, 44 \AA$, and $133 \AA$ for NAgNP, CAgNP, CsAgNP, CsAuNP, $\mathrm{MSiO}_{2}$, and $\mathrm{MSiO}_{2}$ AgNP samples, respectively. It was found that for certain systems, the $R_{g}$ parameter may slightly differ from the predicted values (e.g. slightly higher than a maximum value of the PDDF function $(R)$ for CAgNP (equal $\sim 108 \AA$ while the $R$ is $\sim 67 \AA$ ) which may indicate the occurring disturbances in the sphericity of the system and the imperfections of the real system, which is natural and difficult to exclude. The $R_{\mathrm{g}}$ parameter can be a specific indicator of such a phenomenon. For a system where the particles are perfectly spherical and monodisperse, $R_{\mathrm{g}}$ should be lower than the $\mathrm{R}$ parameter.

Summarizing the part of morphological analysis, it should be stated that the subtle changes in the morphology of supported metal nanoparticles shall be reflected in the scattering effect. Therefore, the nanoparticles can take the specific morphological forms conditioned by the properties of the carrier which can preferentially immobilize the metallic nanoparticles due to their size. In general, the lack of small pores (as in low-porous silica NAgNP) probably effectively maintains the larger forms of nanoparticles. Microporous carriers (as activated carbon CAgNP) may create a three-dimensional, functional layout for retaining nanoparticles with smaller diameters. The above information on the size and shape of the scatterers suggests a significant impact of the surface on the physicochemical properties of the final silver nanophase. Functional groups with affinity to metallic nanoparticles (e.g. in biopolymers) additionally enhance the stabilizing effect. SAXS data show that the most homogeneous metallic phase can be obtained for matrices equipped with a functional group with a high affinity to silver nanoparticles $\left(-\mathrm{OH}\right.$ and $\left.-\mathrm{NH}_{2}\right)[64,65]$. The TEM images confirmed that the spherical shape of nanoparticles was dominated in all populations of nanoparticles (please see Fig. 5_SI). In the following figure, note the sharp distinction between components (boundary) for nanocomposites; however, some of its blurring is visible especially for CAgNP in the form of an additional surrounding layer, which immediately affects the scattering parameters and is signaled in this work (Fig. 5H_SI). The TEM analysis confirmed the vast majority of the SAXS results, although it seems impossible to draw such conclusions based on the TEM images alone. The differences in the sampling of both techniques should also be indicated here. Thus, the important advantages of the SAXS technique in the study of nanocomposite systems are emphasized.

\section{Nanocomposites—the interfacial properties}

The specific surface area and intermediate properties of the nanocomposites were considered according to Porod's theory of scattering data (Fig. 4). The asymptotic behavior of the scattering curves according to Porod's law was observed for all nanocomposites, however, the characteristic plateau of the Porod function was observed at various levels for investigated systems. The linear behavior of the Porod function suggests the building of a separatedphase system with a sharp boundary between phases of various electron density and lack interaction between individual phases. Moreover, the Porod law is better fulfilled when the interface of the object with various electron densities shows a lower degree of polydispersity (exhibit smooth surface). The interfacial surface is plain and clear for all samples. The stability of the phases was confirmed by a well-defined Porod constant value $\left(K_{\mathrm{p}}\right)$ (Table 1$)$. The Porod plot in their asymptotic range is proportional to the specific surface area of the samples. A broad range of linearity was observed for $\mathrm{NAgNP}$ and $\mathrm{MSiO}_{2} \mathrm{AgNP}$ samples (linear range starts at $q \sim 0.12 \AA$ ). It is expected to create well-formed nanoparticles with sharp boundaries on the surface of low porous (NAgNP) and mesoporous ordered silica $\left(\mathrm{MSiO}_{2} \mathrm{AgNP}\right)$.

The linear dependence for other samples $\left(\mathrm{MSiO}_{2}\right.$, CAgNP, and CsAgNP) was noticeable but less pronounced and may indicate the blurring of the interfacial layer (as a result of some gradient in porous structure (for $\mathrm{MSiO}_{2}$ ) or even interfacial interactions (for CAgNP, and CsAgNP)). Typical, the CAgNP surface is rich in various functional groups and may be responsible for local variation and distinct affinity to the metallic particles. In effect, the low linearity of the Porod function may be related to the lower homogeneity of the silver nanoparticles due to the 
Figure 4 Porod plot calculated for investigated systems (slit collimation). The CsAgNP range of the Porod plot was forced at a lower $q$ range due to the SAXS data captured for a film of a certain thickness.
Figure 5 Log- $\log$ plots of SAXS intensity in the powerlaw range of investigated nanocomposites as well as corresponding slopes of the curves.
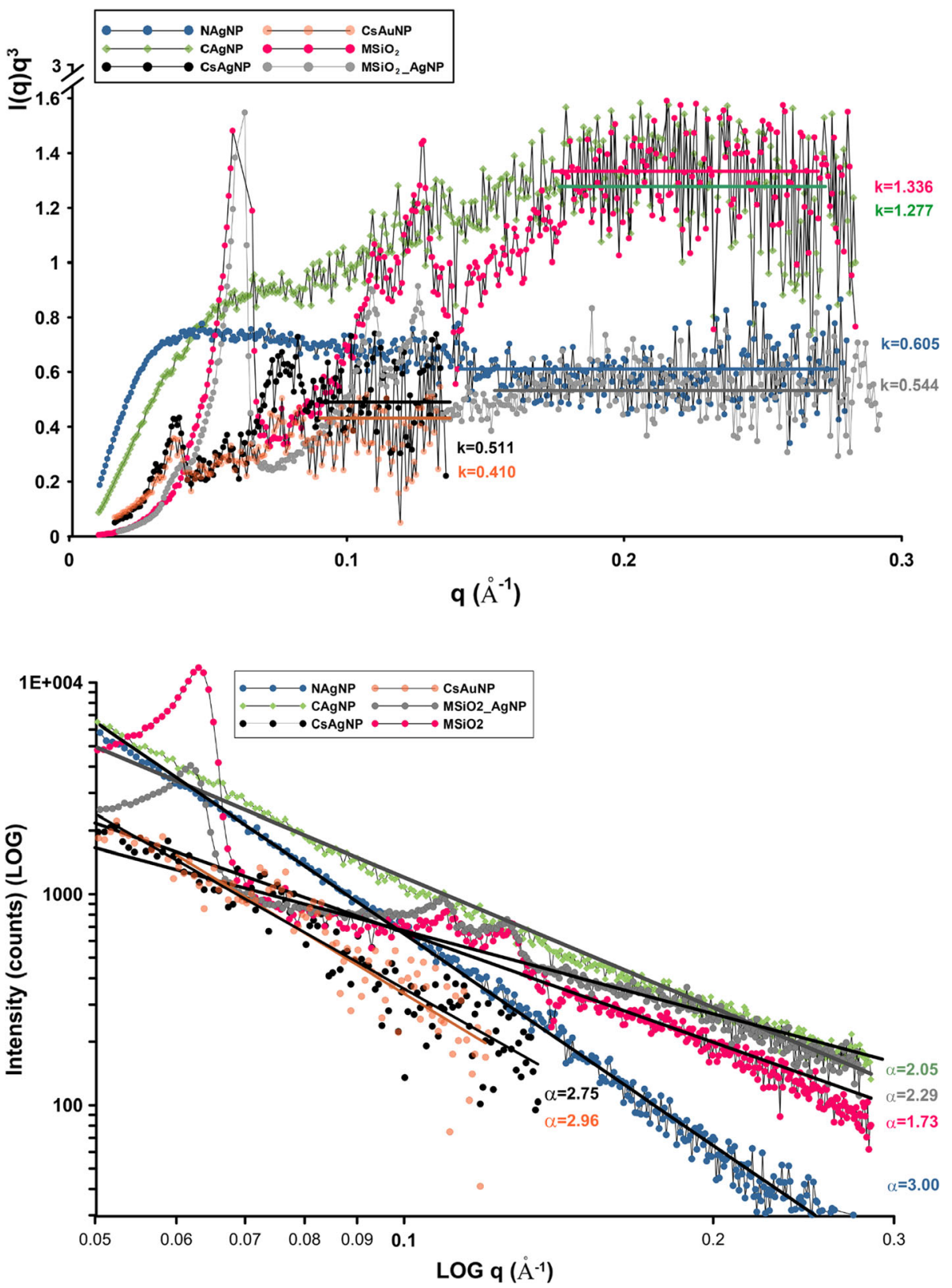

possible interaction between both phases (suggesting also previously by the value of the $R_{g}$ parameter). Confirmation of such state may illustrate previously described blurring the PDDF function and low value of $\alpha$ coefficient describing power law (Fig. 5 see below).

The Porod constant $\left(K_{\mathrm{p}}\right)$ was applied for determining the $\mathrm{S} / \mathrm{V}$ ratio and describing the textural properties of investigated samples. Here, the highest value of the $K_{\mathrm{p}}$ was achieved for the $\mathrm{MSiO}_{2}$ and CAgNP samples and equals $K_{\mathrm{p}}=1.336$ and $K_{\mathrm{p}-}$ $=1.277$, respectively. The $S_{\mathrm{SAXS}}$ values (Table 1 ) were calculated as $2000 \mathrm{~m}^{2} / \mathrm{g}, 950 \mathrm{~m}^{2} / \mathrm{g}$, and $613 \mathrm{~m}^{2} / \mathrm{g}$ for CAgNP, $\mathrm{MSiO}_{2}$ and $\mathrm{MSiO}_{2} \mathrm{AgNP}$. As to be expected the NAgNP and CsAgNP and CsAuNP samples show reduced extensive surface $\left(202 \mathrm{~m}^{2} / \mathrm{g}, 73 \mathrm{~m}^{2} / \mathrm{g}\right.$, and $70 \mathrm{~m}^{2} / \mathrm{g}$, respectively). The $\mathrm{S}_{\mathrm{BET}}$ values amounted to $1468 \mathrm{~m}^{2} / \mathrm{g}, 798 \mathrm{~m}^{2} / \mathrm{g}$, and $573 \mathrm{~m}^{2} / \mathrm{g}$ for $\mathrm{CAgNP}, \mathrm{MSiO}_{2}$, and $\mathrm{MSiO}_{2}$ AgNP samples, respectively. The remaining systems (NAgNP with $S_{\text {BET- }}$ $=200 \mathrm{~m}^{2} / \mathrm{g}$, CsAgNP and CsAuNP with $S_{\mathrm{BET}}=89 \mathrm{~m}^{2} / \mathrm{g}$ and $74 \mathrm{~m}^{2} / \mathrm{g}$, respectively) showed intermediate or low porosity. The $\mathrm{S}_{\mathrm{BET}}$ values calculated from experimental isotherms are presented in 
Table 1 and Fig. 5_SI. Noteworthy the good correlation between $S_{\text {SAXS }}$ data and experimentally performed low-temperature nitrogen adsorption/ desorption data $\left(S_{\mathrm{BET}}\right)$ was obtained. Analysis of the interphase space and correlation of their dimension with the initial porous structure indicate that the scattering effect may be a sum of the effect from pores and nanoparticles. More specifically, a higher value of $S_{\mathrm{SAXS}}$ compared to $S_{\mathrm{BET}}$ may indicate the surface value that becomes inaccessible to adsorbate (nitrogen molecules) due to the incorporation of silver nanoparticles, i.e. indicate a closed porosity of the support after modification.

The power law was complied within a wide range of the scattering vector according to Porod linear range $(q<0.3)$ (Fig. 5). The $\alpha$ exponent was calculated as 1.73, 2.05, 2.29, 2.75, 2.96 and 3.0 for $\mathrm{MSiO}_{2}$, CAgNP, $\mathrm{MSiO}_{2} \mathrm{AgNP}, \mathrm{CsAgNP}, \mathrm{CsAuNP}$ and NAgNP, respectively.

The highest value of the $\alpha$ parameter for NAgNP (corresponds to the exponent of Porod function $\left.\left(I(q) q^{3}\right)\right)$ indicates the smooth interface between domains in a multiphase system and lack of significant heterogeneities in the system of low porous silica nanocomposite. The lower $\alpha$-value suggests the forming of fractal-like structures and scattered heterogeneities in other multiphase systems.

The Porod regime describes the interfacial properties of noble metal-based nanocomposites. The presence of interaction between the nanometric objects and solid surfaces was analyzed by the quality of the interface layers. The linear course of the Porod function indicates the boundary between phases and their diffusing for deviations and was the highest for NAgNP and quite low for CAgNP. Thus surface functionality and affinity level determine the homogeneity of the immobilized species. Analysis of the interface space as $\mathrm{S}_{\mathrm{SAXS}}$ versus $\mathrm{S}_{\mathrm{BET}}$ (closed porosity) may be useful for sorption application.

\section{Conclusions}

Small-angle X-ray scattering (SAXS) as a powerful method to study the structural properties of materials at the nanoscale was applied for the investigation of the structural and interfacial properties of plasmonic structures (AgNP and AuNP) immobilized in various solid matrixes. The all presented data suggest the ability to differentiate the scattering effect depending on the type of the tested system, which proves the differences in the morphology and concentration of the deposited nanometallic layer. Understanding the structure of nanocomposites systems and nanostructured phases at a molecular level is a crucial step in designing functional materials and controlling their modification. The selection methodology was dictated by the application of the fast and meaningful global average way of data determination instead of local and highly dependent procedures. This article helps to discover the structural information of multiphase nanocomposite materials through a relatively simple methodological procedure. The information not only on particle size and shape but also on the internal structure and radial electron density profiles of disordered and partially ordered systems was undoubtedly provided. Here, the various types of nanostructured materials (low porous silica, high porous carbon, biopolymer, and mesoporous ordered silica) were modified by noble metal nanoparticles to create fully functional systems. The plasmonic nanoparticles on the various solid surfaces are reflected in the scattering data and even subtle differences are well marked. The results show that the physicochemical properties of the surface can be crucial during AgNP preparation and stabilization. The shape of supported nanoparticles was close to spherical and size defined to a few nanometers (except for nanoparticles obtained outside the system for $\mathrm{MSiO}_{2}$ AgNP). Thus, the stabilization of metallic nanoparticles seems to be easier in the case of nanoparticles with small size (below $10 \mathrm{~nm}$ ). We found good agreement between SAXS-determined particle size distributions and those calculated from TEM image analysis. It was found that the functionality of the solid phases is crucial in nanostructure stabilization. The overall conclusion points to the enormous possibilities of morphological assessment of the condensed system of nanoparticles.

\section{Acknowledgements}

The research leading to these results received funding from the Project: MINIATURA1-National 
Science Centre (NCN) of Poland. Project number: 2017/01/X/ST5/00229.

Supplementary Information: The online version contains supplementary material available at http s:/ / doi.org/10.1007/s10853-021-06127-2.

Open Access This article is licensed under a Creative Commons Attribution 4.0 International License, which permits use, sharing, adaptation, distribution and reproduction in any medium or format, as long as you give appropriate credit to the original author(s) and the source, provide a link to the Creative Commons licence, and indicate if changes were made. The images or other third party material in this article are included in the article's Creative Commons licence, unless indicated otherwise in a credit line to the material. If material is not included in the article's Creative Commons licence and your intended use is not permitted by statutory regulation or exceeds the permitted use, you will need to obtain permission directly from the copyright holder. To view a copy of this licence, visit http://creativecommons.org/licen ses/by/4.0/.

\section{References}

[1] Tanahashi M (2010) Development of fabrication methods of filler/polymer nanocomposites: with focus on simple meltcompounding-based approach without surface modification of nanofillers. Materials 3:1593-1619. https://doi.org/10.33 90/ma3031593

[2] Stodolak E, Paluszkiewicz C, Bogun M, Blazewicz M (2009) Nanocomposite fibres for medical applications. J Mol Struct 924-926:208-213. https://doi.org/10.1016/j.molstruc. 2009.01.018

[3] Sajid P, Devasena T (2012) Synthesis and characterization of silica nanocomposites for bone applications. Int Res J Pharm 3:173-177

[4] Ahmad M, Manzoor K, Singh S, Ikram S (2017) Chitosan centered bionanocomposites for medical specialty and curative applications: a review. Int J Pharm 529:200-217. h ttps://doi.org/10.1016/j.ijpharm.2017.06.079

[5] Thostenson ET, Li C, Chou T-W (2005) Nanocomposites in context. Compos Sci Technol 65:491-516. https://doi.org/10. 1016/j.compscitech.2004.11.003

[6] Braun P, Najafzadeh Khoee AA, Habibolahzadeh A (2012) Nanocomposite; Science and Technology
[7] Wu C-J, Gaharwar AK, Schexnailder PJ, Schmidt G (2010) Development of biomedical polymer-silicate nanocomposites: a materials science perspective. Materials (Basel) 3:2986-3005. https://doi.org/10.3390/ma3052986

[8] Sedghi R, Asadi S, Heidari B, Heravi MM (2017) TiO2/ polymeric supported silver nanoparticles applied as superior nanocatalyst in reduction reactions. Mater Res Bull 92:65-73. https://doi.org/10.1016/j.materresbull.2017.02. 004

[9] Huo C, Jiang H, Lu Y et al (2019) Tunable photoluminescence effect from $\mathrm{ZnO}$ films of $\mathrm{Ag}$-decorated localized surface plasmon resonance by varying positions of $\mathrm{Ag}$ nanoparticles. Mater Res Bull 111:17-23. https://doi.org/10. 1016/j.materresbull.2018.10.037

[10] Pastoriza-Santos I, Kinnear C, Pérez-Juste J, Mulvaney P, Liz-Marzán LM (2018) Plasmonic polymer nanocomposites. Nat Rev Mater 3:375-391. https://doi.org/10.1038/s41578018-0050-7

[11] Ferhan AR, Kim D-H (2016) Nanoparticle polymer composites on solid substrates for plasmonic sensing applications. Nano Today 11:415-434. https://doi.org/10.1016/j.na ntod.2016.07.001

[12] Liz-Marzán LM (2006) Tailoring surface plasmons through the morphology and assembly of metal nanoparticles. Langmuir 22:32-41. https://doi.org/10.1021/la0513353

[13] Ravichandran M, Oza G, Velumani S et al (2016) Plasmonic/magnetic multifunctional nanoplatform for cancer theranostics. Sci Rep 6:34874. https://doi.org/10.1038/sre p34874

[14] Stafford S, Serrano Garcia R, Gun'ko YK (2018) Multimodal magnetic-plasmonic nanoparticles for biomedical applications. Appl Sci 8:97. https://doi.org/10.3390/a pp8010097

[15] Deng Y, Cai Y, Sun Z et al (2010) Multifunctional mesoporous composite microspheres with well-designed nanostructure: a highly integrated catalyst system. J Am Chem Soc 132:8466-8473. https://doi.org/10.1021/ja1025744

[16] Park M, Hwang CSH, Jeong K-H (2018) Nanoplasmonic alloy of $\mathrm{Au} / \mathrm{Ag}$ nanocomposites on paper substrate for biosensing applications. ACS Appl Mater Interfaces 10:290-295. https://doi.org/10.1021/acsami.7b16182

[17] Ahmad R, Griffete N, Lamouri A, Felidj N, Chehimi MM, Mangeney C (2015) Nanocomposites of gold nanoparticles@molecularly imprinted polymers: chemistry, processing, and applications in sensors. Chem Mater 27:5464-5478. https://doi.org/10.1021/acs.chemmater.5b00138

[18] Li Y, Schluesener HJ, Xu S (2010) Gold nanoparticle-based biosensors. Gold Bull 43:29-41. https://doi.org/10.1007/ BF03214964 
[19] Modi V, Shrives Y, Sharma A, Sen PK, Bohidar S (2014) Review on green polymer nanocomposite and their applications. Int J Innov Res Sci Eng Technol 3:17651-17656. h ttps://doi.org/10.15680/IJIRSET.2014.0311079

[20] Cherian BM, Leão AL, de Souza SF et al (2011) Cellulose nanocomposites with nanofibres isolated from pineapple leaf fibers for medical applications. Carbohydr Polym 86:1790-1798. https://doi.org/10.1016/j.carbpol.2011.07. 009

[21] Yan D, Wang F, Zhao Y et al (2009) Production of a high dispersion of silver nanoparticles on surface-functionalized multi-walled carbon nanotubes using an electrostatic technique. Mater Lett 63:171-173. https://doi.org/10.1016/j.ma tlet.2008.09.018

[22] Shi K, Pang X, Zhitomirsky I (2016) Silver nanoparticle assembly on carbon nanotubes triggered by reductive surfactant coating. Mater Lett 178:128-131. https://doi.org/10. 1016/j.matlet.2016.05.005

[23] Chatterjee U, Jewrajka SK, Guha S (2009) Dispersion of functionalized silver nanoparticles in polymer matrices: stability, characterization, and physical properties. Polym Compos 30:827-834. https://doi.org/10.1002/pc.20655

[24] Fratoddi I (2017) Hydrophobic and hydrophilic Au and Ag nanoparticles. Breakthroughs and perspectives. Nanomaterials (Basel). https://doi.org/10.3390/nano8010011

[25] Pauksch L, Hartmann S, Rohnke M et al (2014) Biocompatibility of silver nanoparticles and silver ions in primary human mesenchymal stem cells and osteoblasts. Acta Biomater 10:439-449. https://doi.org/10.1016/j.actbio.2013.09. 037

[26] Emamifar A, Kadivar M, Shahedi M, Solimanian-Zad S (2012) Effect of nanocomposite packaging containing Ag and Zno on reducing pasteurization temperature of orange juice. J Food Process Preserv 36:104-112. https://doi.org/10. 1111/j.1745-4549.2011.00558.x

[27] Chen X, Yan J-K, Wu J-Y (2016) Characterization and antibacterial activity of silver nanoparticles prepared with a fungal exopolysaccharide in water. Food Hydrocolloids 53:69-74. https://doi.org/10.1016/j.foodhyd.2014.12.032

[28] Gallocchio F, Cibin V, Biancotto G et al (2016) Testing nano-silver food packaging to evaluate silver migration and food spoilage bacteria on chicken meat. Food Addit Contam Part A 33:10631071. https://doi.org/10.1080/19440049.201 6.1179794

[29] Ruland W, Smarsly B (2004) SAXS of self-assembled oriented lamellar nanocomposite films: an advanced method of evaluation. J Appl Crystallogr 37:575-584. https://doi.org/ 10.1107/S0021889804011288

[30] Verma RK, Velikov V, Kander RG, Marand H, Chu B, Hsiao BS (1996) SAXS studies of lamellar level morphological changes during crystallization and melting in PEEK. Polymer 37:5357-5365. https://doi.org/10.1016/S0032-3861(96) 00387-4

[31] Becker C, Kutsch B, Krug H, Kaddami H (1998) BSAXS and TEM investigations on thermoplastic nanocomposites containing functionalized silica nanoparticles. J Sol-Gel Sci Technol 13:499-502. https://doi.org/10.1023/A: 1008602118194

[32] Zaioncz S, Dahmouche K, Soares B (2010) SAXS characterization of new nanocomposites based on epoxy resin/ siloxane/mma/acrylic acid hybrid materials. Macromol Mater Eng 295:243-255. https://doi.org/10.1002/mame. 200900286

[33] Monteiro V, Bacarji E, Gomes O, Rocco Lahr F, Christoforo A (2015) Theoretical and experimental studies of timber composite beams reinforced by cold formed steel sheets. Int J Mater Eng 5:50-63. https://doi.org/10.5923/j.ijme.201505 03.03

[34] Ganguly S, Mondal S, Das P et al (2019) An insight into the physico-mechanical signatures of silylated graphene oxide in poly(ethylene methyl acrylate) copolymeric thermoplastic matrix. Macromol Res 27:268-281. https://doi.org/10.1007/ s13233-019-7039-y

[35] Higgins JS (2016) Neutron scattering from polymers: five decades of developing possibilities. Annu Rev Chem Biomol Eng 7:1-28. https://doi.org/10.1146/annurev-chembioeng-0 80615-034429

[36] Oberdisse J (2007) Adsorption and grafting on colloidal interfaces studied by scattering techniques. Curr Opin Colloid Interface Sci 12:3-8. https://doi.org/10.1016/j.cocis.20 06.11 .001

[37] Preschilla N, Sivalingam G, Abdul Rasheed AS, Tyagi S, Biswas A, Bellare JR (2008) Quantification of organoclay dispersion and lamellar morphology in poly(propylene)-clay nanocomposites with small angle X-ray scattering. Polymer 49:4285-4297. https://doi.org/10.1016/j.polymer.2008.07. 030

[38] Takeoka H, Fukui N, Sakurai S, Nakamura Y, Fujii S (2014) Nanomorphology characterization of sterically stabilized polypyrrole-palladium nanocomposite particles. Polym J 46:704-709. https://doi.org/10.1038/pj.2014.44

[39] Tobler DJ, Benning LG (2013) In situ and time resolved nucleation and growth of silica nanoparticles forming under simulated geothermal conditions. Geochim Cosmochim Acta 114:156-168. https://doi.org/10.1016/j.gca.2013.03.045

[40] Garcia PRAF, Prymak O, Grasmik V et al (2020) An in situ SAXS investigation of the formation of silver nanoparticles and bimetallic silver-gold nanoparticles in controlled wetchemical reduction synthesis. Nanoscale Adv 2:225-238. h ttps://doi.org/10.1039/C9NA00569B 
[41] Mourdikoudis S, Pallares RM, Thanh NTK (2018) Characterization techniques for nanoparticles: comparison and complementarity upon studying nanoparticle properties. Nanoscale 10:12871-12934. https://doi.org/10.1039/ C8NR02278J

[42] Milenin SA, Selezneva EV, Tikhonov PA et al (2021) Hybrid polycarbosilane-siloxane dendrimers: synthesis and properties. Polymers 13:606-621. https://doi.org/10.3390/ polym13040606

[43] JM Mata-Padilla, CA Ávila-Orta, FJ Medellín-Rodríguez, JA Valdéz-Garza, A Torres-Martínez (2012) Study of fracture behavior of polypropylene/MWCNT and polypropylene/mMMT nanocomposites by small angle $\mathrm{x}$-ray scattering (SAXS). MRS Proceedings 1371: imrc11. https://doi.org/10. 1557/opl.2012.163

[44] Blanchet C, Svergun D (2012) Small-angle x-ray scattering on biological macromolecules and nanocomposites in solution. Annu Rev Phys Chem 64:37-54. https://doi.org/10.11 46/annurev-physchem-040412-110132

[45] Lipfert J, Doniach S (2007) Small-angle X-ray scattering from RNA, proteins, and protein complexes. Annu Rev Biophys Biomol Struct 36:307-327. https://doi.org/10.1146 /annurev.biophys.36.040306.132655

[46] Majorošová J, Schroer MA, Tomašovičová N et al (2020) Effect of the concentration of protein and nanoparticles on the structure of biohybrid nanocomposites. Biopolymers 111:e23342. https://doi.org/10.1002/bip.23342

[47] Sandí G, Joachin H, Kizilel R, Seifert S, Carrado KA (2003) In situ SAXS studies of the structural changes of polymer nanocomposites used in battery applications. Chem Mater 15:838-843. https://doi.org/10.1021/cm020670z

[48] Alcántara R, Jaraba M, Lavela P, Tirado JL (2002) NiCo2O4 spinel: first report on a transition metal oxide for the negative electrode of sodium-ion batteries. Chem Mater 14:2847-2848. https://doi.org/10.1021/cm025556v

[49] Park GO, Yoon J, Park E et al (2015) In operando monitoring of the pore dynamics in ordered mesoporous electrode materials by small angle $x$-ray scattering. ACS Nano 9:5470-5477. https://doi.org/10.1021/acsnano.5b01378

[50] Schmidt W, Amenitsch H (2020) High dynamics of vapor adsorption in ordered mesoporous carbon CMK-5: a small angle X-ray scattering study. J Phys Chem C 124:21418-21425. https://doi.org/10.1021/acs.jpcc.0c05356

[51] Folkertsma L, Zhang K, Czakkel O et al (2017) Synchrotron SAXS and impedance spectroscopy unveil nanostructure variations in redox-responsive porous membranes from poly(ferrocenylsilane) poly(ionic liquid)s. Macromolecules 50:296-302. https://doi.org/10.1021/acs.macromol.6b02318

[52] Engström J, Jimenez AM, Malmström E (2020) Nanoparticle rearrangement under stress in networks of cellulose nanofibrils using in situ SAXS during tensile testing. Nanoscale 12:6462-6471. https://doi.org/10.1039/ C9NR10964A

[53] Tajima H, Penttilä PA, Imai T, Yamamoto K, Yuguchi Y (2019) Observation of in vitro cellulose synthesis by bacterial cellulose synthase with time-resolved small angle X-ray scattering. Int J Biol Macromol 130:765-777. https://doi.org/ 10.1016/j.ijbiomac.2019.02.167

[54] Zienkiewicz-Strzałka M, Pasieczna-Patkowska S, Kozak M, Pikus S (2013) Silver nanoparticles incorporated onto ordered mesoporous silica from Tollen's reagent. Appl Surf Sci 266:337-343. https://doi.org/10.1016/j.apsusc.2012.12. 021

[55] Groetsch C (1984) The theory of Tikhonov regularization for Fredholm equations of the first kind. Pitman Advanced Pub, London

[56] Gregg SJ, Sing KSW, Salzberg HW (1967) Adsorption surface area and porosity. J Electrochem Soc 114(11):279C. https://doi.org/10.1149/1.2426447

[57] Yan S, Wu Z, Yu H et al (2014) Time-resolved small-angle $\mathrm{X}$-ray scattering study on the growth behavior of silver nanoparticles. J Phys Chem C 118:11454-11463. https://doi. org/10.1021/jp502482c

[58] Bowden B, Davies M, Davies PR et al (2018) The deposition of metal nanoparticles on carbon surfaces: the role of specific functional groups. Faraday Discuss 208:455-470. https://doi. org/10.1039/C7FD00210F

[59] Xue Y, Li X, Li H, Zhang W (2014) Quantifying thiol-gold interactions towards the efficient strength control. Nat Commun 5:4348. https://doi.org/10.1038/ncomms5348

[60] Gommes CJ, Prieto G, de Jongh PE (2016) Small-angle scattering analysis of empty or loaded hierarchical porous materials. J Phys Chem C 120:1488-1506. https://doi.org/ 10.1021/acs.jpcc.5b09556

[61] Dou Y, Liu H, Peng J, Li M, Li W, Yang F (2016) A green method for preparation of CNT/CS/AgNP composites and evaluation of their catalytic performance. J Mater Sci 51:5685-5694. https://doi.org/10.1007/s10853-016-9871-1

[62] Zhang H, Peng M, Cheng T et al (2018) Silver nanoparticlesdoped collagen-alginate antimicrobial biocomposite as potential wound dressing. J Mater Sci 53:14944-14952. h ttps://doi.org/10.1007/s10853-018-2710-9

[63] Regiel-Futyra A, Kus-Liśkiewicz M, Sebastian V et al (2017) Development of noncytotoxic silver-chitosan nanocomposites for efficient control of biofilm forming microbes. RSC Adv 7:52398-52413. https://doi.org/10.1039/C7RA08359A

[64] Hassan MK, Abukmail A, Hassiba AJ, Mauritz KA, Elzatahry AA (2018) PVA/chitosan/silver nanoparticles electrospun nanocomposites: molecular relaxations investigated by 
modern broadband dielectric spectroscopy. Nanomaterials 8:888. https://doi.org/10.3390/nano8110888

[65] Zienkiewicz-Strzałka M, Deryło-Marczewska A (2020) Small AgNP in the biopolymer nanocomposite system. Int J Mol Sci 21:9388. https://doi.org/10.3390/ijms21249388
Publisher's Note Springer Nature remains neutral with regard to jurisdictional claims in published maps and institutional affiliations. 